Article

\title{
Genomic Features of Cladobotryum dendroides, Which Causes Cobweb Disease in Edible Mushrooms, and Identification of Genes Related to Pathogenicity and Mycoparasitism
}

\author{
Rong Xu ${ }^{1,2}$, Xiaochen Liu ${ }^{1,2}$, Bing Peng ${ }^{1,2}$, Peibin Liu ${ }^{1,2}$, Zhuang $\mathrm{Li}^{3}$, Yueting Dai ${ }^{1, *}$ and \\ Shijun Xiao ${ }^{1, *}$ \\ 1 Internationally Cooperative Research Center of China for New Germplasm Breeding of Edible Mushroom, \\ Jilin Agricultural University, Changchun 130118, China; xurong@jlau.edu.cn (R.X.); \\ liuxiaochen18@jlau.edu.cn (X.L.); pengbing@jlau.edu.cn (B.P.); liupeibin@jlau.edu.cn (P.L.) \\ 2 College of Plant Protection, Jilin Agricultural University, Changchun 130118, China \\ 3 Shandong Provincial Key Laboratory for Biology of Vegetable Diseases and Insect Pests, College of Plant \\ Protection, Shandong Agricultural University, Tai'an 271018, China; zhuangli@sdau.edu.cn \\ * Correspondence: daiyueting18@jlau.edu.cn (Y.D.); xiaosj@gooalgene.com (S.X.); \\ Tel.: +86-431-8453-2989 (Y.D. \& S.X.)
}

Received: 20 February 2020; Accepted: 16 March 2020; Published: 20 March 2020

\begin{abstract}
Cladobotryum dendroides, which causes cobweb disease in edible mushrooms, is one of the major fungal pathogens. Our previous studies focused on the genetic and morphological characterization of this fungus, as well as its pathogenicity and the identification of appropriate fungicides. However, little is known about the genome characters, pathogenic genes, and molecular pathogenic mechanisms of $C$. dendroides. Herein, we reported a high-quality de novo genomic sequence of $C$. dendroides and compared it with closely-related fungi. The assembled $C$. dendroides genome was $36.69 \mathrm{Mb}$, consisting of eight contigs, with an N50 of $4.76 \mathrm{Mb}$. This genome was similar in size to that of $C$. protrusum, and shared highly conserved syntenic blocks and a few inversions with C. protrusum. Phylogenetic analysis revealed that, within the Hypocreaceae, Cladobotryum was closer to Mycogone than to Trichoderma, which is consistent with phenotypic evidence. A significant number of the predicted expanded gene families were strongly associated with pathogenicity, virulence, and adaptation. Our findings will be instrumental for the understanding of fungi-fungi interactions, and for exploring efficient management strategies to control cobweb disease.
\end{abstract}

Keywords: Hypomyces rosellus; Lentinula edodes; comparative genomics; evolution; pathogenicity; secretory protein

\section{Introduction}

Cobweb disease, together with dry bubble (Lecanicillium fungicola), green mold (Trichoderma aggressivum), and wet bubble (Mycogone perniciosa), are currently considered the four most serious diseases of edible mushrooms that are caused by parasitic fungi [1]. These fungal diseases pose threats to mushroom production, and cause economic losses in all mushroom-growing countries worldwide [2,3]. The incidence of these diseases is increasing at an alarming rate, causing serious damage to a variety of edible mushrooms, including Agaricus bisporus [4,5], Pleurotus ostreatus [6], P. eryngii [7], Flammulina velutipes [3], Hypsizygus marmoreus [8], and Ganoderma sichuanensis [9]. Cobweb disease is characterized by the rapid growth of abundant coarse mycelium over the affected mushrooms [10]. Typical symptoms of this disease are cottony fluffy white or yellowish to pink colonies on mushrooms, rapid colonization, 
and the covering of the host basidiomata by parasitic mycelia; these symptoms lead to host decay [11]. Several species of Cladobotryum, including C. dendroides, C. protrusum, C. mycophilum, C. varium, C. multiseptatum, and C. verticillatum have been identified as pathogens causing cobweb disease $[10,12]$.

The sexual morph of the Cladobotryum is classified in the genus Hypomyces [13]. C. dendroides, the anamorph conidial state of Hypomyces rosellus, was first shown to cause cobweb disease in the edible mushroom A. bisporus [10]. Recently, C. dendroides was also found in Lentinula edodes, which seriously affects the quality and yield [14,15]. In previous studies, we have reported on several aspects of $C$. dendroides, including taxonomic classification, disease incidence, genetic and morphological characterization, pathogenicity, and fungicide screening [16]. However, the pathogenesis of this fungus at the molecular level remains largely unknown. Genome analysis will facilitate the identification of pathogenicity-related genes and the characterization of pathogen-mushroom interactions. However, sequenced genomes in this genus (Hypomyces/Cladobotryum) are scarce. To date, only the genomes of C. protrusum and H. perniciosa (the sexual morph of $M$. perniciosa) have been released $[17,18]$. C. protrusum is the only species of Cladobotryum for which a genome is available [17]. It is imperative to obtain additional genome data in order to rapidly identify pathogenic genes and characterize fungi-fungi interactions in the Cladobotryum.

The development of single-molecule real-time (SMRT) sequencing technology has tremendously increased the quality of pathogen genomic sequences [19]. Associated advances have improved the identification of pathogenicity-related genes and revealed the molecular mechanisms underlying pathogenesis. To date, several pathogenic genomes have been sequenced using Pacific Biosciences (PacBio) Sequel or the RSII platform $[17,18,20]$. With these available genomic sequences, it is possible to determine the evolutionary relationships among fungi [21-24], as well as to explore the evolution of nutritional mode. In addition, numerous gene clusters associated with pathogenicity have been identified, including secretory proteins, membrane transport proteins, pathogen-host interaction (PHI) genes, fungal virulence factors, and fungal $G$ proteins $[17,18]$. In addition, some expanded or contracted orthologous, species-specific genes and positive selective genes, including protein kinases, serine peptidases, cell-wall proteins, carbohydrate-active enzymes (CAZymes), secondary metabolites (SMs), and P450, were shown to be involved in biological control activity, pathogenesis, and mycoparasitism [21,22,24].

In this study, we performed the whole-genome sequencing of $C$. dendroides, a mycoparasite causing cobweb disease in L. edodes. The objectives of our study were: (1) to present a high-quality reference genome for $C$. dendroides, and to explore the genomic features and genes related to pathogenicity and mycoparasitism; and (2) to conduct a comparative genome analysis within the genus Cladobotryum and estimate its evolution. Our assembled genome will further expand genomic datasets for comparative genomic analysis in Hypocreaceae and in other mycoparasitic fungi.

\section{Results and Discussion}

\subsection{Genome Sequencing and Assembly}

We obtained genomic DNA from a single spore pure culture of $C$. dendroides (CCMJ2807) isolated from L. edodes. The genome was sequenced using the Sequel sequencing platform, and yielded $5.40 \mathrm{~Gb}$ of sequence data at $164 \times$ coverage. A total of $38.48 \mathrm{Mb}$ of reads were assembled into eight contigs, with a contig N50 of $4.76 \mathrm{Mb}$, an N90 of $4.40 \mathrm{Mb}$, and a maximum span of $7.02 \mathrm{Mb}$. The size of the assembled genome was smaller than previously reported for C. protrusum (39.09 Mb) [17] and M. perniciosa $(44.00 \mathrm{Mb})$ [18], but larger than other species within the Hypocreaceae, including T. longibrachiatum $(32.24 \mathrm{Mb})$ [25], T. reesei $(33.39 \mathrm{Mb})$ [26], and Escovopsis weberi $(27.20 \mathrm{Mb})$ [27]. The guanine-cytosine (GC) content of the $C$. dendroides genome was $48.2 \%$. The completeness of the assembled genome was evaluated by mapping the Benchmarking Universal Single-Copy Orthologs (BUSCO) set of 3725 fungal genes to the assembly. This analysis identified 3662 complete BUSCOs in the $C$. dendroides gene sets, which indicated a high-quality genome with an estimated completeness of $98.31 \%$ (Table 1 and 
Figure 1). Telomeres comprised of TTAGGG repeats are commonly identified at the molecular end of the linear chromosomes in filamentous fungi [28]. Among the eight contigs, four contigs (utg0, 1, 3 , and 11) contained complete telomere-to-telomere structures, including remarkably regular repeat sequences ([T]TTAGGG). The remaining four contigs (utg2, 4, 9, and 83) could also be arranged into two complete telomere pairs, as each was comprised of one telomeric repeat. Consequently, there were six potential chromosomes in the $C$. dendroides genome, similar to related Trichoderma species, which have three to seven chromosomes [22]. These results indicated that our assembled genome was contiguous and sufficient for further analysis. Our new, high-quality, whole genome sequence of C. dendroides will provide insights into its evolution and pathogenic mechanisms.

Table 1. Features of available Cladobotryum genomes.

\begin{tabular}{ccc}
\hline Genome Features & C. dendroides & C. protrusum \\
\hline Sequence coverage $(\mathrm{X})$ & 164 & 160 \\
Genome size $(\mathrm{Mb})$ & 36.69 & 39.09 \\
Total number of contigs & 8 & 18 \\
Contig N50 $(\mathrm{bp})$ & $4,995,562$ & $4,973,539$ \\
Contig N90 $(\mathrm{bp})$ & $4,617,620$ & $1,928,814$ \\
GC content $(\%)$ & 48.20 & 47.84 \\
Transposable elements $(\%)$ & 4.37 & 2.59 \\
Protein coding genes & 9548 & 11,003 \\
tRNAs & 225 & 242 \\
BUSCO estimates $(\%)$ & 98.31 & 99.70 \\
\hline
\end{tabular}




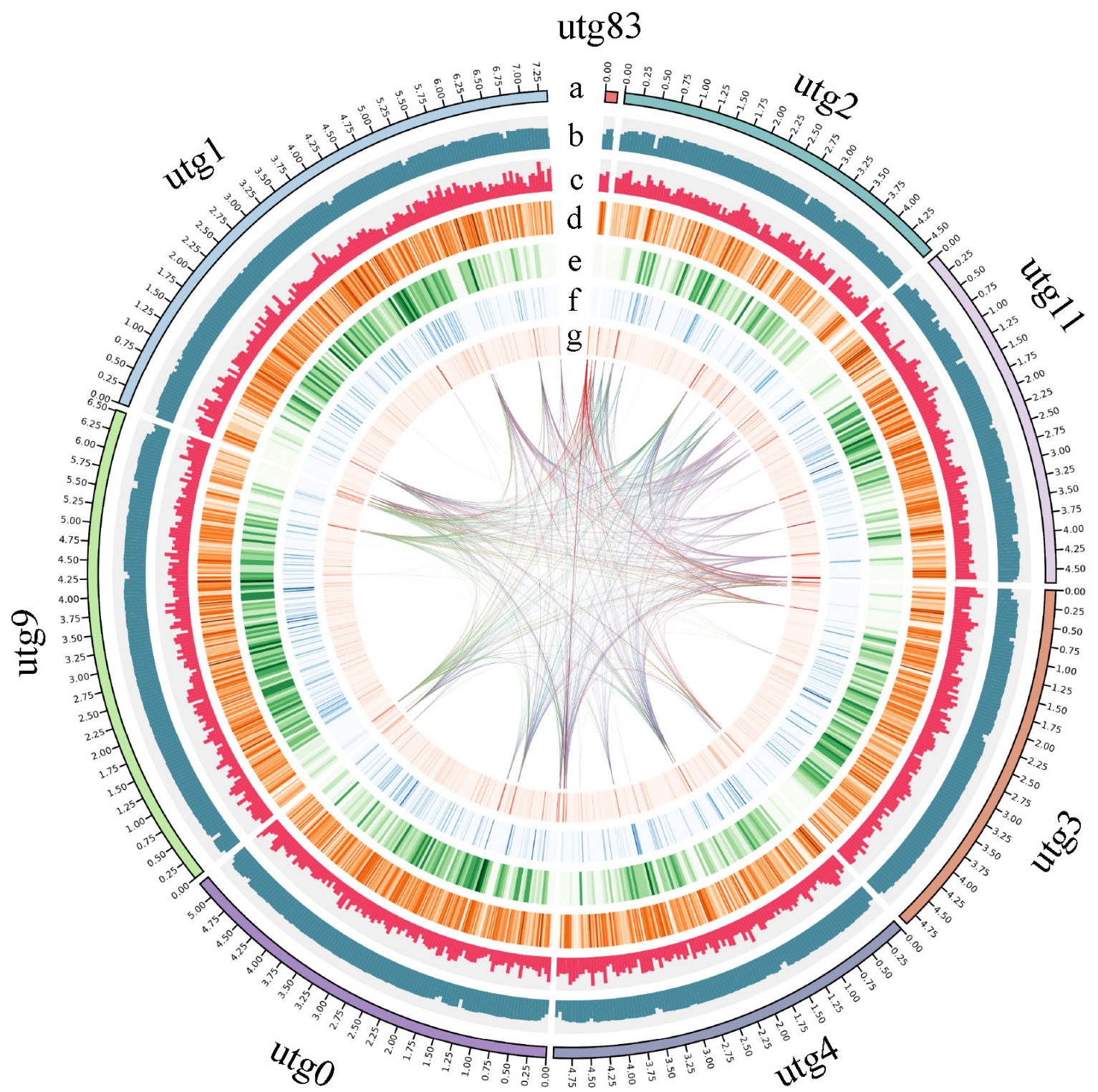

Figure 1. Genome map of Cladobotryum dendroides. Outer to inner concentric circles show (a) assembly contig number; (b) guanine-cytosine (GC) content; (c) sequence coverage; (d) gene density; (e) Benchmarking Universal Single-Copy Orthologs (BUSCO) estimates; (f) DNA repeat content; (g) long interspersed nuclear element (LINE), short interspersed element (SINE), and long terminal repeat (LTR) content.

\subsection{Gene Prediction and Annotation}

There were $\sim 1.95 \mathrm{Mb}$ of repetitive elements in the C. dendroides genome, which represented $5.07 \%$ of the total genome; this was consistent with previous findings in C. protrusum [17]. These repetitive elements comprised all of the major transposable element (TE) types, including DNA repeats, long interspersed nuclear elements (LINEs), short interspersed elements (SINEs), and long terminal repeats (LTRs). LTRs were the most abundant TE, representing $2.25 \%(0.86 \mathrm{Mb})$ of the genome, followed by LINEs $(0.47 \% ; 0.79 \mathrm{Mb})$ and DNA transposable elements $(0.36 \%)$. Variations in genome size and structure, as well as in the numbers of predicted genes in the genome of a given species, are potentially closely associated with differences in repetitive DNA content; these differences may be due to natural selection, species lifestyle, and ecological niche [29]. C. dendrodides and C. protrusum have fewer repetitive elements, especially TEs, as compared M. perniciosa [17]. This might be because M. perniciosa has more efficient DNA removal mechanisms [18], and might explain the smaller size 
of the M. perniciosa genome. Genome size might be affected by host- and environment-associated adaptations as well as evolution [30,31]. We also performed a high-throughput screening of simple sequence repeat (SSR) loci, and identified 2520 SSR loci, including 817 dinucleotide repeats (DNRs), 644 trinucleotide repeats (TNRs), 782 tetranucleotide repeats (TTNRs), 203 pentanucleotide repeats (PNRs), and 74 hexanucleotide repeats (HNRs). These repeats included 454 types of motif sequences. The mean motif length was $27.72 \mathrm{bp}$, and the longest motif was $224 \mathrm{bp}$ long, consisting of the TTNR "TTAT" repeated 56 times. The largest numbers of DNR, TNR, PNR, and HNR repeats were 47, 65, 26, and 12 , respectively.

Gene predictions were performed using a combination of homology-based and de novo-based approaches. Using these approaches, we identified 9548 protein coding genes, with an average length of $1819.49 \mathrm{bp}$, in the $C$. dendroides genome. Across the identified genes, the average sizes of the exons and introns were 564.7 and $108.75 \mathrm{bp}$, respectively, which was similar to other species of Hypocreaceae $[17,18]$. We then functionally annotated these coding genes against seven typical databases, and found that 9369 (98.13\%) genes had homologs in at least one database. Specifically, 9345 (99.74\%) were homologous to known proteins in the National Center for Biotechnology Information (NCBI) non-redundant database (Nr); 4637 (49.49\%) to known proteins in the Nucleotide Sequence Database (Nt); 5003 (53.40\%) to known proteins in the Eukaryotic Clusters of Orthologous Groups (KOG) database; $7230(77.17 \%)$ to known proteins in SwissProt; $4446(47.45 \%)$ to known proteins in the Gene Ontology (GO) database; 5203 (55.53\%) to known proteins in the Kyoto Encyclopedia of Genes and Genomes (KEGG); and 5381 (57.43\%) to known proteins in Pfam. The total length of the non-coding RNA (ncRNA) was 34,626 bp, accounting for $0.09 \%$ of the assembled genome. The ncRNA contained 225 transfer RNAs (tRNAs), 26 small nuclear RNAs (snRNAs), and 56 ribosome RNAs (rRNAs).

\subsection{Identification of Mating-Type Idiomorphs}

We identified two previously-characterized MAT genes (MAT1-1-2 and MAT1-1-3) grouped together in the genome at a single locus (contig utg0) (Supplementary Figure S1). The MAT 1-2 idiomorph was not found in C. dendroides, incongruent with results in C. protrusum and M. perniciosa, but consistent with results in Macrophomina phaseolina, T. harzianum, and T. longibrachiatum [21,22]. In addition, the genes adjacent to the MAT genes were all located upstream on this locus, including complex I intermediate-associated protein 30 (CIA30), anaphase-promoting complex (APC5), cytochrome C oxidase subunit VIa (Cox), and DNA lyase (APN2). Notably, the flanking genes in C. dendroides were the same as those in M. perniciosa (contig utg16) and were oriented in the same direction [18]. The identification of these mating-type structures in the $C$. dendroides genome provides some insights into the sexual lifestyle of this organism.

\subsection{CAZymes Analysis}

At the beginning of infection, pathogens primarily use CAZymes to destroy the polysaccharide component of the host cell wall [32]. We identified $327 \mathrm{C}$. dendroides genes across the six categories of CAZymes. We found that 163 genes, representing the largest proportion of the genome, encoded glycoside hydrolases (GHs), 103 genes encoded glycosyl transferases (GTs), 27 genes encoded carbohydrate-binding modules (CBMs), and 27 genes encoded auxiliary activities (AAs). The carbohydrate esterases (CEs; 4 genes) and polysaccharide lyases (PLs; 3 genes) were poorly represented in the genome. C. dendroides had fewer CAZymes than several other species in the Hypocreaceae: T. harzianum (439), T. virens (434), T. guizhouense (423), C. protrusum (364), T. reesei (360), T. koningii (353), and M. perniciosa (338) (Figure 2). 


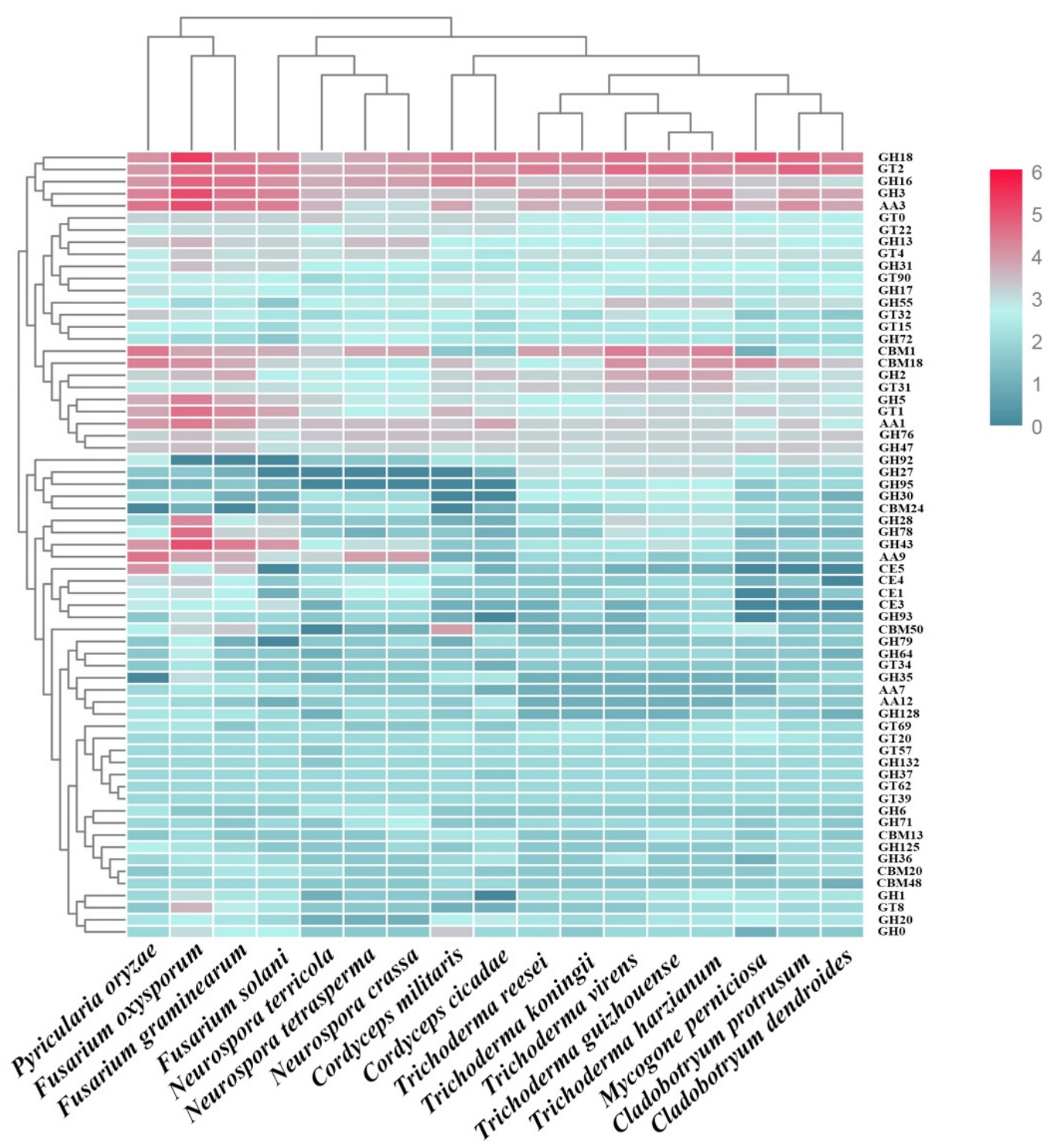

Figure 2. Comparative analysis of the genes encoding carbohydrate-active enzymes (CAZymes) in Cladobotryum dendroides and 16 other fungi. Over-represented (6 to 0$)$ values are depicted as Z-scores for each row in the heatmap.

Across the three pathogens (C. dendroides, C. protrusum, and M. perniciosa), most genes encoded GH and GT enzymes, which might be used to degrade the host cell barrier during the fungi-fungi infection process. Most of the differences between the two Cladobotryum and three Trichoderma (T. harzianum, T. virens, and T. guizhouense) genomes were due to the high copy number of GH and CBM families in these Trichoderma genomes. Most chitinase- and cellulose-degrading enzymes are categorized within GH classes. The ability of $C$. dendroides to decompose chitin is suggested by the abundance of genes that belongs to the GH families. Of the GH families, GH18 is encoded by the most genes (19), followed by GH3 (13). GH18 contains the class III and V chitinases. The abundance of GH18 and GH3 was consistent with the efficient degradation of chitinase, cellulose, and hemicellulose [33], and suggested that these enzymes might play a role in the $C$. dendroides genome. In addition, we found that the C. dendroide genome contained a large number of CBMs, which occur as fusions to GHs, CEs, or AAs. CBM18 is most abundant in the CBM family in C. dendroides: approximately nine residues in modules. These modules were attached to a number of chitinase catalytic domains. Chitin-binding functions have been demonstrated in many cases [34]. Our results suggested that $C$. dendroides might destroy the host cell wall by secreting a large amount of chitinase during infection. The CBM1 and CBM50 binding 
domains have been previously described in the order Hypocreales [22,35]. We found additional CBMs that putatively bind to starch, xylanase, fructans, cellulose, and glucans. This implied that $C$. dendroides makes full use of these domains, which might result in the faster and more competitive degradation of the respective polymers.

AAs, which are involved in lignin degradation, also account for a large proportion of the CAZymes in C. dendroides (27). The relative abundances of the AA families were larger than M. perniciosa (22) [18], but fewer than C. protrusum (34) [17]. Of the AA enzymes, AA3 was the most abundant family (13), followed by AA1 (6), AA7 (2), AA12 (2), and AA9 (1). A previous study showed that the AA3_2 subfamily (including both aryl alcohol oxidase and glucose 1-oxidase), combined with AA9 lytic polysaccharide monooxygenases (LPMOs), can catalyze the efficient cleavage of cellulose [36]. We also detected 11 AA3_2 subfamilies in C. dendroides, compared with 14 in C. protrusum [17]. The abundant GT2 (21 genes) also suggested that $C$. dendroides has abundant enzymes associated with cellulose synthase and chitin synthase.

\subsection{Analysis of Secondary Metabolites (SMs)}

SM are important virulence determinants in several fungal pathogens, and are also essential for stress tolerance and cellular signaling [37]. We identified $116 \mathrm{SM}$ genes in C. dendroides using antiSMASH, compared with 143 in C. protrusum [17]. The SM genes in C. dendroides included 48 type 1 polyketide synthases (T1PKS), 36 non-ribosomal polypeptide synthetases (NRPS), 17 terpene synthases (TS), nine NRPS-like genes, three fungal-RiPPs, two siderophores, and one indole encoding gene clusters. More PKSs and NRPSs were identified in C. dendroides than in C. protrusum [17], M. perniciosa [18], and Trichoderma spp. [22]. In addition, we used Natural Product Domain Seeker (NaPDoS) analysis to search for genes encoding secondary metabolites in $\mathrm{C}$. dendroides. A total of 100 genes encoding SMs were identified, including various pathway products such as HC-toxin, cyclo, compl, ituri, prist, tyroc, liche, bacit, act, cdaps, surfa, and micro. These results suggested that C. dendroides might synthetize many essential biologically-active compounds.

\subsection{Prediction and Analysis of Pathogenicity-Related Genes}

Pathogens can secrete many proteins that support the colonization of the host surface during infection [38]. To identify potential protein-coding genes related to pathogenicity and virulence in the C. dendroides genome, BLAST searches against the pathogen-host interaction database (PHI) and the database of fungal virulence factors (DFVF) were performed. We predicted 419 and 153 genes with $\geq 70 \%$ identity in the PHI and DFVF, respectively, representing $4.39 \%$ and $1.60 \%$, respectively, of the predicted total genes (Supplementary Tables S1 and S2). Additionally, 76 genes were identified in both databases. Of the PHI genes, reduced virulence $(203,48.45 \%)$ was the most abundant followed by unaffected pathogenicity $(139,33.17 \%)$, loss of pathogenicity $(28,6.68 \%)$, lethal $(40,9.55 \%)$, increased virulence (hypervirulence) $(5,1.19 \%)$, chemistry target $(3,0.72 \%)$, and enhanced antagonism $(1,0.24 \%)$. No effectors (plant avirulence determinants) were found with $\geq 70 \%$ identity.

Using SECRETOOL, 371 candidate secretory proteins were predicted. Remarkably, 287 peptidase proteins with an identity $\geq 70 \%$ were identified against the peptidase database (MEROPS) database (Supplementary Table S3). Among these secretory proteins, seven homologs were identified in MEROPS, and three homologs were identified in PHI. Fungal effectors can play a vital molecular role in fungus-plant communication, targeting and regulating the phytohormone signaling of hosts by changing or operating them [39]. A set of 400 putative effector proteins were predicted using the filtered set SignalP (identify $\geq 70 \%$ ), out of which seven were unique genes. Previous studies have predicted several effector proteins in C. protrusum [17] and M. perniciosa [18]. Pathogens may optimize their own effector sets to adapt to hosts [40]. Overall, these fungal effectors in C. dendroides might lead to the adaptation of pathogens with a broad host range to a specific host over time [41]. We also identified 336 (3.52\%), 175 (1.83\%), and 48 (0.50\%) genes encoding for cytochrome P450 (CYP), major 
facilitator superfamily (MFS) transporters (Pfam domain assignment), and ATP-binding cassette (ABC) transporters, respectively.

\subsection{Comparative and Evolutionary Analysis}

To explore gene family evolution in $C$. dendroides, we aligned its coding sequences (CDSs) with those of C. protrusum and 15 other representative fungi downloaded from the NCBI: M. perniciosa [18], Pyricularia oryzae [42], five Trichoderma (T. virens [43], T. reesei [26], T. koningii (https://www.ncbi. nlm.nih.gov/genome/?term=Trichoderma++koningii), T. guizhouense (https://www.ncbi.nlm.nih.gov/ genome/?term=Trichoderma++guizhouense), and T. harzianum [44]), three Neurospora (N. terricola [45], N. tetrasperma [46], and N. crassa [47]), two Cordyceps (Cor. militaris [48] and Cor. Cicadae [49]), and three Fusarium (F. solani (https://www.ncbi.nlm.nih.gov/genome/?term=Fusarium+solani), F. oxysporum [50], and F. graminearum [51]). A total of 8957 ortholog families (groups), comprising 10,983 proteins, were produced, as well as 166 orphans that showed no homology with any other proteins in the dataset. A total of 7684 and 8418 groups (in C. dendroides and C. protrusum, respectively) had homologs in the other fungi tested, of which about 2523 were conserved across all of the compared genomes (Figure 3A). C. dendroides and C. protrusum shared the most orthologous gene families (6356). C. dendrodides shared the fewest unique orthologous gene families (10) with C. protrusum (36), M. perniciosa (92), and T. reeseirep (resentative of Trichoderma, 28) (Figure 3B). These unique genes might be relevant to the resistance and adaption abilities of $C$. dendroides.

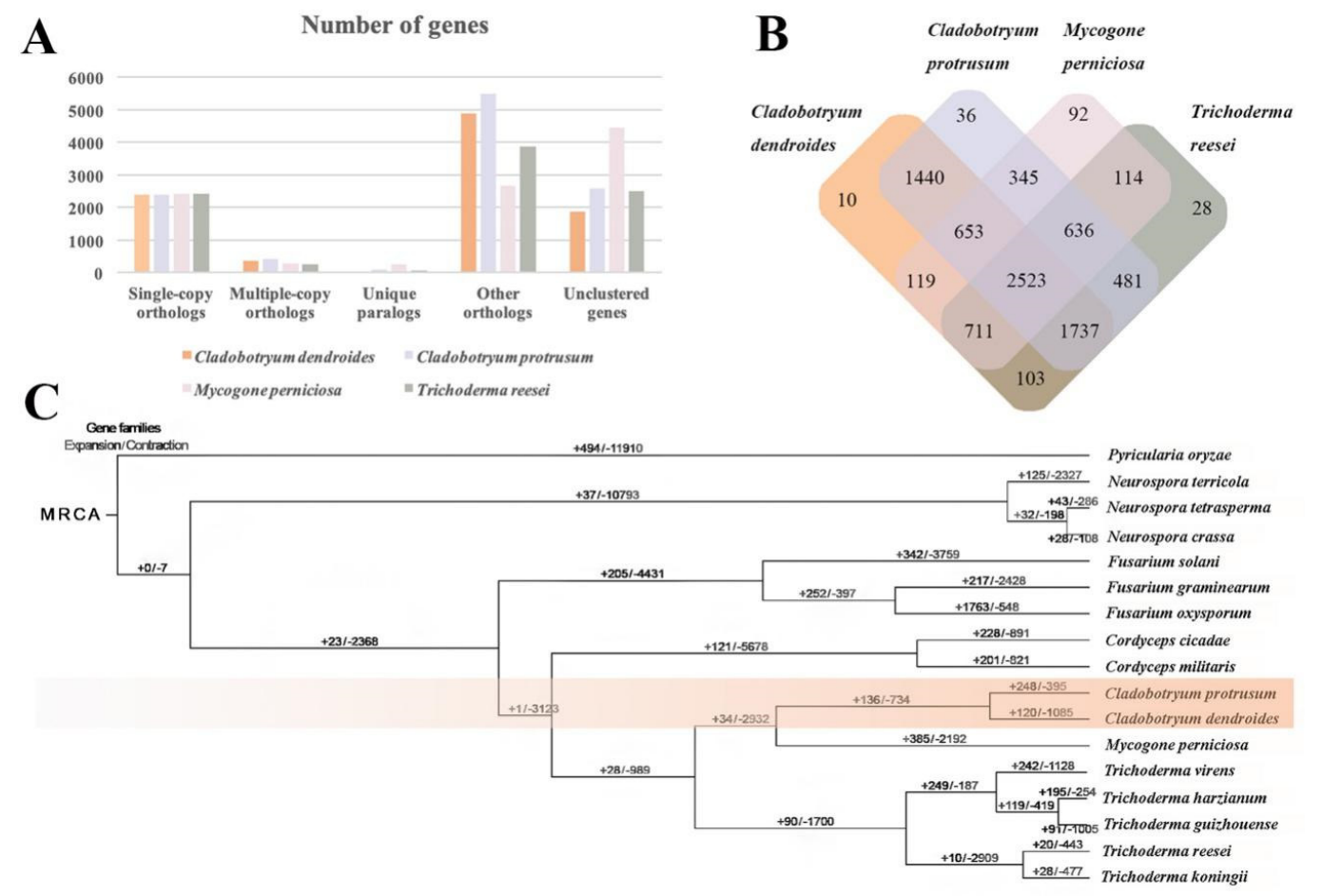

Figure 3. Genomic analyses, comparing Cladobotryum dendroides with other fungi. (A) Orthologous genes in the genomes of $C$. dendroides, C. protrusum, Mycogone perniciosa, and Trichoderma reesei. (B) Unique and shared gene families among the four genomes. Overlaps indicate shared gene families. (C) Phylogenetic tree of $C$. dendroides and 16 other fungal species, constructed using the maximum-likelihood method. MRCA, most recent common ancestor.

We next phylogenomically analyzed 2287 single copy orthologs that were conserved across all of the fungi analyzed (Figure 3C). Our phylogeny of the 17 species indicated that Cladobotryum, Mycogone, and Trichoderma were distantly-related genera within the family Hypocreaceae; this was consistent with previous reports $[18,22,43]$. Furthermore, Cladobotryum was more genetically similar to Mycogone 
than to Trichoderma, which was consistent with morphological taxonomy, traditional classification, and life history. Our phylogeny also recovered C. dendroides and C. protrusum in a monophyletic clade, and showed that these species diverged relatively recently. Based on phylogenetic placement, we also inferred that, within the Trichoderma clade, subgroup I (consisting of T. virens, T. harzianum, and T. guizhouense) evolved independently of subgroup II (T. reesei and T. koningii), and occurred species differentiation. This conclusion was consistent with that of Kubicek et al. [43]. These results indicated that our phylogeny tree accurately reflected evolutionary relationships.

We found that gene family contraction in $C$. dendrodides was more common that gene family expansion. A total of 120 gene families in $C$. dendroides expanded during evolution, fewer than in C. protrusum (248) and M. perniciosa (385) (Figure 3C). Functional analyses showed that the significant expansion of gene families in $C$. dendroides were mainly associated with the major facilitator superfamily (MFS), ankyrin repeats (three copies), and NACHT domains $(P<0.05)$. MFS transporter proteins allow the uptake of sugars to permit growth on varied substrates [52]. MFS gene families with three duplications were expanded in $C$. dendrodides, providing this fungus with the versatile ability to utilize sugars for growth. NACHT domains and ankyrin repeats are two kinds of heterokaryon incompatibility protein (HET) related domains. NACHT domains are predicted NTPases, which play a role in programmed cell death (PCD); PCD might be ancient, preceding the radiation of animals and fungi $[53,54]$. The ankyrin proteins modulate protein-protein interactions among HET proteins [55]. HET and related genes are essential for genetic information transfer in Pyrenochaeta lycopersici [55]. Interestingly, MFS transporters and ankyrin repeats were also expanded in M. perniciosa and Trichoderma species $[18,22]$. Furthermore, in order to adapt to unfavorable conditions and to host defense mechanisms, pathogens must generate variation [55]. Therefore, this expansion of multiple gene families in $C$. dendrodides might play a significant role in the pathogenicity of this species, as well as its ability to effectively infect macrofungi, to tolerate varied climates, and to adapt to different host lifestyles [56]. We identified 2.75-fold more contracted gene families in C. dendroides (1085) than have been found in C. protrusum (395) [17], but twice as many were identified in M. perniciosa (2192) [18]. These contracted gene families may serve to decrease the host range of Cladobotryum and Mycogone compared to Trichoderma species [18]. In addition, all of the noticeably contracted gene families were predicated to be P450 members (CYP5150A2, CYP5151A1, and CYP620H1) $(P<0.05)$. We identified 278 significantly positively selected genes in $C$. dendroides $(P<0.01)$, which were mainly related to transport and catabolism, the metabolism of cofactors and vitamins, the immune system, signal transduction, sorting and degradation, and cell growth and death. These genes might play a crucial role in the adaptation of $C$. dendroides to harsh environments, and in its mycoparasitic lifestyle.

Whole-genome collinearity analyses for $C$. dendroides and C. protrusum were then performed (Figure 4). Most of the contigs in C. dendroides were highly conserved syntenic blocks shared with C. protrusum. For example, contig9 and contig0 from C. dendroides corresponded with contig102 and contig83, respectively, from C. protrusum. We identified a few inversions and rearrangements between the homologous regions of the two genomes. For example, we observed a large inversion between contig3 from $C$. dendroides and contig67 from C. protrusum, as well as rearrangements in contig1 and contig4 from C. dendroides and contig14 and contig28 of C. protrusum. This suggested that a set of fusions or breakages might have arisen among the chromosomes of Cladobotryum species during their long evolutionary history. Notably, we observed an inversion between the middle region of contig9 from C. dendroides (145 genes) and the middle part of contig83 from C. protrusum (150 genes). Functional analyses showed that the $145 \mathrm{C}$. dendroides genes were mainly associated with GH18 (chitinase), GH35 (beta-galactosidase), serine/threonine-protein kinase, MFS, P450, and transcription factors. Additional genes located in other inversions and rearranged regions were related to amidase, glutathione S-transferase, GH3, GH16, signal peptidases, and zinc-finger proteins (C2H2 type). This genomic diversity might play a crucial role in the morphological formation, lifestyle, adaptation, and resistance of these two species. 


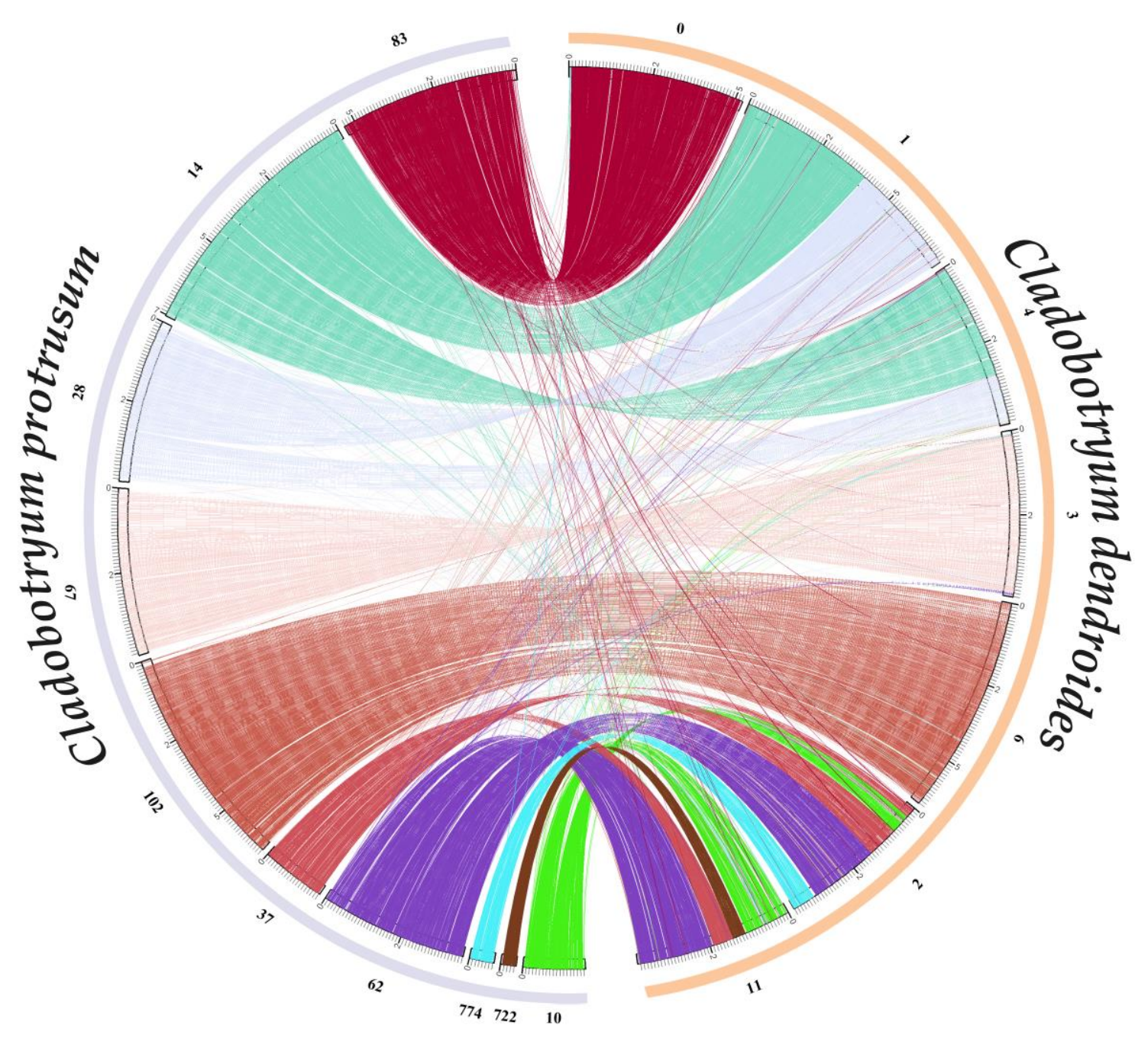

Figure 4. The genome collinearity analysis of the Cladobotryum dendroides and C. protrusum based on protein-coding genes.

\section{Materials and Methods}

\subsection{Culture Conditions and Genomic DNA Extraction}

A single virulent $C$. dendroides spore was isolated from a specimen of $L$. edodes infected with symptomatic cobweb disease in Qingyuan, Zhejiang Province (China). This strain was defined as CCMJ 2808, and it was used for whole genome sequencing. We confirmed the identification of this strain as $C$. dendroides using morphological characters, molecular analysis of ITS DNA sequences, and artificial inoculation [15]. After culturing strain CCMJ 2808 in potato dextrose agar (PDA) at $25^{\circ} \mathrm{C}$ in the dark for three days, mycelial mats of pure isolates were harvested and frozen using liquid nitrogen. Genomic DNA extraction was performed using Nuclean plant genomic DNA kits (CWBIO, Beijing, China), following the manufacturer's protocol. We measured DNA integrity, purity, and concentration using $0.6 \%$ agarose gel, a Nanodrop 2000 (Thermo Fischer Scientific, Life Technologies, USA), and a Qubit 3.0 (Thermo Fischer Scientific, Life Technologies, USA), respectively. Strain CCMJ 2808 was maintained in the Engineering Research Center of Chinese Ministry of Education for Edible and Medicinal Fungi (ERCCMEEMF, Changchun, China). 


\subsection{Genome Sequencing and Assembly}

We constructed 20-kb libraries for $C$. dendroides, and the genome was sequenced with a PacBio Sequel long-read sequencing platform $[17,18,23,57]$. To redress mismatch rate and increase sequencing read lengths, we performed next generation sequencing. SMARTdenovo (https://github.com/ruanjue/ smartdenovo) was used for the de novo assembly of the genome. BUSCOs [58] were used to assess the completeness of the genome assembly. The assembled genome of $C$. dendroides was submitted to the NCBI database and deposited with the accession number WWCI01000000.

\subsection{Gene Prediction and Genome Annotation}

Repeat elements (including SSRs) and non-coding genes were predicted as described previously $[17,18]$. Coding genes were predicted using a combination of sequence homology and de novo prediction. The homology approach was based on representative reference genomes, including those of Cor. militaris [48], T. reesei [26], C. protrusum [17], F. oxysporum [50], and F. graminearum [51]. De novo predictions were performed using Augustus [59] and GlimmerHMM [60]. Finally, MAKER2 [61] was used to combine the gene models generated by both de novo prediction and protein homology matching. The predicted genes were used for subsequent analyses. The predicted protein-coding genes were functionally annotated against seven databases, with a cutoff e-value of $1 \times 10^{-5}$ : NCBI Nr, Nt, KOG [62], SwissProt [63], GO [64], KEGG [65], and Pfam [66]. The presence of mating-type genes in C. dendroides was confirmed by homologous alignment with mating-type genes and flanking sequences from the order Hypocreales. Biological sequences 1.0 was used to draw the gene structures [67].

\subsection{Secretome Analysis and Pathogenicity-Related Genes}

Secretory signal peptides were analyzed using the web-based analysis pipeline SECRETOOL, which is specifically designed to screen and identify putative secretome in fungi [68]. Protease candidates were screened by searching secretory proteins against the MEROPS database [69]. Pathogenic genes were identified using the PHI (http://www.phi-base.org/) [70] and DFVF (http://sysbio.unl.edu/ DFVF/Download.php) [71] databases. Effector candidates were predicted in combination with the SignalP 5.0 server (http://www.cbs.dtu.dk/services/SignalP-5.0/). Then, virulence-associated genes, Cytochrome P450s, CAZymes, and SMs were predicted as described by Sossah et al. (2019) [17].

\subsection{Orthological, Phylogenetic, Evolutionary, and Whole-Genome Collinearity Analyses}

OrthoMCL (v.2.0.9) [72] was used to identify the orthologous gene families based on the CDSs of C. dendroides, C. protrusum, M. perniciosa, and 14 other selected genomes downloaded from the NCBI. The shared single-copy genes were screened and aligned using Clustal omega [73]. To construct a genome-based phylogenetic tree, we used the maximum likelihood (ML) algorithm in RAxML [74], with P. oryzae as the outgroup. Computational Analysis of Gene Family Evolution (CAFE) 3.1 [75] was used to predict the expansion and contraction of the orthologous gene families; those with a $P$-value $<0.05$ were considered to be significant candidates. Positively selected genes were identified using the branch-site model of the CodeML tool in PAML [76]. The whole-genome collinearity of C. dendrodides and C. protrusum was analyzed using the Python version of MCscan, with default parameters (https://github.com/tanghaibao/jcvi/wiki/MCscan- (Python- version)).

\section{Conclusions}

In this study, we obtained a high-quality genome sequence of $C$. dendroides, a causal agent of cobweb disease on cultivated edible mushrooms, using the PacBio Sequel platform. From our genomic and comparative analyses, we drew three conclusions. First, compared with M. perniciosa, Cladobotryum (C. dendroides and C. protrusum) lost many repeated sequences over evolutionary time, which resulted in a contraction in the sizes of both genomes. Second, $C$. dendroides shared highly conserved syntenic blocks with C. protrusum. In addition, within the Hypocreaceae, Cladobotryum was more closely related 
to Mycogone than to Trichoderma. Third, a significant number of the predicted expanded gene families in C. dendroides were strongly associated with pathogenicity, virulence, resistance, and adaptation, providing insights into the molecular biology, genetics, evolution, and pathogenicity of this species. Overall, our genomic data provide a valuable resource with which to accelerate functional studies of the pathogen C. dendroides, subsequently supporting the development of control strategies as well as breeding programs designed to improve cobweb disease resistance in edible mushrooms.

Supplementary Materials: The following are available online at http://www.mdpi.com/2076-0817/9/3/232/s1, Table S1: Annotated pathogen-host interaction (PHI) genes in the Cladobotryum dendroides genome, Table S2: List of fungal virulence factor genes in the Cladobotryum dendroides genome, based on the database of fungal virulence factors (DFVF), Table S3: List of protease genes in the Cladobotryum dendroides genome, based on the MEROPS database, Figure S1: Mating-type loci (MAT) analysis of Cladobotryum dendroides. Genomic architecture of the MAT and flanking genes in C. dendroides. The arrows represent the orientation of the MAT1-1 genes APC5 (Anaphase-promoting complex subunit 5), APN2 (DNA lyase), CIA30 (Complex I intermediate-associated protein 30), and CoxVIa (Cytochrome c oxidase subunit VIa).

Author Contributions: Conceptualization, Y.D. and S.X.; Writing-original draft and formal analysis, R.X. and Y.D.; Data curation, R.X. and X.L.; Investigation, Z.L.; Methodology, R.X. and X.L.; Software, B.P. and P.L.; Supervision, Y.D. and S.X.; Writing - review \& editing, R.X., Y.D. and S.X. All of the authors have read and approved the final draft. All authors have read and agreed to the published version of the manuscript.

Funding: This research was funded by the National Natural Science Foundation of China (no. 31700012); The Scientific Research Foundation for the Returned Overseas Chinese Scholars; Changchun Science and Technology Project (no. 15SS11); The Special Fund for Agro-scientific Research in the Public Interest (no. 201503137); The Program of Creation and Utilization of Germplasm of Mushroom Crop of "111" Project (no. D17014); and National-level International Joint Research Centre (2017B01011).

Acknowledgments: We thank LetPub (www.letpub.com) for its linguistic assistance during the preparation of this manuscript.

Conflicts of Interest: The authors declare that they do not have any conflict of interest.

\section{References}

1. Fletcher, J.T.; Gaze, R.H. Mushroom Pest and Disease Control: A Color Handbook, ed.; Manson Publishing Ltd. Academic Press: San Diego, CA, USA, 2008; p. 192.

2. Adie, B.; Grogan, H.; Archer, S.; Mills, P. Temporal and spatial dispersal of Cladobotryum conidia in the controlled environment of a mushroom growing room. Appl. Environ. Microbiol. 2006, 72, 7212-7217. [CrossRef] [PubMed]

3. Kim, H.-K.; Seok, S.-J.; Kim, G.-P.; Moon, B.-J.; Terashita, T. Occurrence of disease caused by Cladobotryum varium on Flammulina velutipes in Korea. Korean J. Mycol. 1999, 27, 415-419.

4. Back, C.-G.; Kim, Y.-H.; Jo, W.-S.; Chung, H.; Jung, H.-Y. Cobweb disease on Agaricus bisporus caused by Cladobotryum mycophilum in Korea. J. Gen. Plant Pathol. 2010, 76, 232-235. [CrossRef]

5. Grogan, H.M.; Gaze, R.H. Fungicide resistance among Cladobotryum spp.-causal agents of cobweb disease of the edible mushroom Agaricus bisporus. Mycol. Res. 2000, 104, 357-364. [CrossRef]

6. Gea, F.J.; Navarro, M.J.; Suz, L.M. Cobweb disease on oyster culinary-medicinal mushroom (Pleurotus ostreatus) caused by the mycoparasite Cladobotryum mycophilum. J. Plant Pathol. 2019, 101, 349-354. [CrossRef]

7. Gea, F.J.; Navarro, M.J.; Suz, L.M. First report of Cladobotryum mycophilum causing cobweb on cultivated king oyster mushroom in Spain. Plant Dis. 2011, 95, 1030. [CrossRef]

8. Back, C.-G.; Lee, C.-Y.; Seo, G.-S.; Jung, H.-Y. Characterization of species of Cladobotryum which cause cobweb disease in edible mushrooms grown in Korea. Mycobiology 2012, 40, 189-194. [CrossRef]

9. Zuo, B.; Lu, B.H.; Liu, X.L.; Wang, Y.; Ma, G.L.; Gao, J. First report of Cladobotryum mycophilum causing cobweb on Ganoderma lucidum cultivated in Jilin province, China. Plant Dis. 2016, 100, 1239. [CrossRef]

10. Carrasco, J.; Navarro, M.J.; Gea, F.J. Cobweb, a serious pathology in mushroom crops: A review. Span. J. Agric. Res. 2017, 15, e10R01. [CrossRef]

11. Potocnik, I.; Vukojević, J.; Stajić, M.; Rekanović, E.; Milijašević, S.; Todorović, B.; Stepanović, M. In vitro toxicity of selected fungicides from the groups of benzimidazoles and demethylation inhibitors to Cladobotryum dendroides and Agaricus bisporus. J. Environ. Sci. Health B 2009, 44, 365-370. [CrossRef] 
12. McKay, G.J.; Egan, D.; Morris, E.; Scott, C.; Brown, A.E. Genetic and morphological characterization of Cladobotryum species causing cobweb disease of mushrooms. Appl. Environ. Microbiol. 1999, 65, 606-610. [CrossRef] [PubMed]

13. Tamm, H.; Põldmaa, K. Diversity, host associations, and phylogeography of temperate aurofusarin-producing Hypomyces/Cladobotryum including causal agents of cobweb disease of cultivated mushrooms. Fungal Biol. 2013, 117, 348-367. [CrossRef] [PubMed]

14. Gea, F.J.; Navarro, M.J.; Suz, L.M. First report of cobweb disease caused by Cladobotryum dendroides on shiitake mushroom (Lentinula edodes) in spain. Plant Dis. 2018, 102, 1030. [CrossRef]

15. Wu, X.Y.; Fu, Y.P.; Li, Y. Biological characteristics of Cladobotryum dendroides, a causal pathogen of Lentinula edodes cobweb disease. Mycosystema 2019, 38, 646-657.

16. Gams, W.; Hoozemans, A.C.M. Cladobotryum-Konidienformen von Hypomyces-Arten. Persoonia 1970, 6, 95-110.

17. Sossah, F.L.; Liu, Z.H.; Yang, C.T.; Okorley, B.A.; Sun, L.; Fu, Y.P.; Li, Y. Genome sequencing of Cladobotryum protrusum provides insights into the evolution and pathogenic mechanisms of the cobweb disease pathogen on cultivated mushroom. Genes 2019, 10, 124. [CrossRef]

18. Li, D.; Sossah, F.L.; Sun, L.; Fu, Y.P.; Li, Y. Genome analysis of Hypomyces perniciosus, the causal agent of wet bubble disease of button mushroom (Agaricus bisporus). Genes 2019, 10, 417. [CrossRef]

19. Grigoriev, I.V.; Nikitin, R.; Haridas, S.; Kuo, A.; Ohm, R.; Otillar, R.; Riley, R.; Salamov, A.; Zhao, X.; Korzeniewski, F.; et al. MycoCosm portal: Gearing up for 1000 fungal genomes. Nucleic Acids Res. 2014, 42, D699-D704. [CrossRef]

20. Gong, L.; Wu, Y.; Jian, Q.J.; Yin, C.X.; Li, T.T.; Gupta, V.K.; Duan, X.W.; Jiang, Y.M. Data descriptor: Complete genome sequencing of the luminescent bacterium, Vibrio qinghaiensis sp. Q67 using PacBio technology. Sci. Data 2018, 5, 170105. [CrossRef]

21. Wang, B.; Liang, X.F.; Gleason, M.J.; Zhang, R.; Sun, G.Y. Comparative genomics of Botryosphaeria dothidea and B. kuwatsukai, causal agents of apple ring rot, reveals both species expansion of pathogenicity-related genes and variations in virulence gene content during speciation. IMA Fungus 2018, 9, 243-257. [CrossRef]

22. Christian, P.K.; Andrei, S.S.; Komal, C.; Gelsomina, M.; Bernard, H.; Jian, Z.; Feng, C.; Alexey, G.K.; Eva, M.K.; Alan, K.; et al. Evolution and comparative genomics of the most common Trichoderma species. BMC Genom. 2019, 20, 485.

23. Dai, Y.T.; Sun, L.; Yin, X.L.; Gao, M.; Zhao, Y.T.; Jia, P.S.; Yuan, X.H.; Fu, Y.P.; Li, Y. Pleurotus eryngii genomes reveal evolution and adaptation to the gobi desert environment. Front. Microbiol. 2019, 10, 2024. [CrossRef] [PubMed]

24. Dai, Y.T.; Li, X.; Song, B.; Sun, L.; Yang, C.T.; Zhang, X.; Wang, Y.F.; Zhang, Z.W.; Fu, Y.P.; Li, Y. Genomic analyses provide insights into the evolutionary history and genetic diversity of Auricularia species. Front. Microbiol. 2019, 10, 2255. [CrossRef] [PubMed]

25. Druzhinina, I.S.; Chenthamara, K.; Zhang, J.; Atanasova, L.; Yang, D.; Miao, Y.; Rahimi, M.J.; Grujic, M.; Cai, F.; Pourmehdi, S.; et al. Massive lateral transfer of genes encoding plant cell wall-degrading enzymes to the mycoparasitic fungus Trichoderma from its plant-associated hosts. PLoS Genet. 2018, 14, e1007322. [CrossRef] [PubMed]

26. Martinez, D.; Berka, R.M.; Henrissat, B.; Saloheimo, M.; Arvas, M.; Baker, S.E.; Chapman, J.; Chertkov, O.; Coutinho, P.M.; Cullen, D.; et al. Genome sequencing and analysis of the biomass-degrading fungus Trichoderma reesei (syn. Hypocrea jecorina). Nat. Biotechnol. 2008, 26, 553-560. [CrossRef] [PubMed]

27. De Man, T.J.B.; Stajich, J.E.; Kubicek, C.P.; Teiling, C.; Chenthamara, K.; Atanasova, L.; Druzhinina, I.S.; Levenkova, N.; Birnbaum, S.S.L.; Barribeau, S.M.; et al. Small genome of the fungus Escovopsis weberi, a specialized disease agent of ant agriculture. Proc. Natl. Acad. Sci. USA 2016, 113, 3567-3572. [CrossRef] [PubMed]

28. Cohn, M.; Liti, G.; Barton, D.B.H. Telomeres in fungi. Top. Curr. Genet. 2005, 15, 101-130.

29. Xia, E.H.; Yang, D.R.; Jiang, J.J.; Zhang, Q.J.; Liu, Y.; Liu, Y.L.; Zhang, Y.; Zhang, H.B.; Shi, C.; Tong, Y.; et al. The caterpillar fungus, Ophiocordyceps sinensis, genome provides insights into highland adaptation of fungal pathogenicity. Sci. Rep. 2017, 7, 1806-1816. [CrossRef]

30. Bennett, R.J.; Turgeon, B.G. Fungal sex: The Ascomycota. Microbiol. Spectr. 2016, 4, FUNK-0005-2016. [CrossRef] 
31. Agrawal, Y.; Narwani, T.; Subramanian, S. Genome sequence and comparative analysis of clavicipitaceous insect-pathogenic fungus Aschersonia badia with Metarhizium spp. BMC Genom. 2016, 17, 367. [CrossRef]

32. Bashyal1, B.M.; Rawat, K.; Sharma, S.; Kulshreshtha, D.; Krishnan, S.G.; Singh, A.K.; Dubey, H.; Solanke, A.U.; Sharma, T.R.; Aggarwal, R. Whole genome sequencing of Fusarium fujikuroi provides insight into the role of secretory proteins and cell wall degrading enzymes in causing bakanae disease of rice. Front. Plant Sci. 2017, 8, 2013. [CrossRef] [PubMed]

33. Huang, Q.S.; Xie, X.L.; Liang, Ge.; Gong, F.; Wang, Ye.; Wei, X.Q.; Wang, Q.; Ji, Z.L.; Chen, Q.X. The GH18 family of chitinases: Their domain architectures, functions and evolutions. Glycobiology 2012, 22, 23-34. [CrossRef] [PubMed]

34. Sánchez-Vallet, A.; Mesters, J.R.; Thomma, B.P.H.J. The battle for chitin recognition in plant-microbe interactions. FEMS Microbiol. Rev. 2015, 39, 171-183. [CrossRef] [PubMed]

35. Akcapinar, G.B.; Kappel, L.; Sezerman, O.U.; Seidl-Seiboth, V. Molecular diversity of LysM carbohydrate-binding motifs in fungi. Curr. Genet. 2015, 61, 103-113. [CrossRef]

36. Garajova, S.; Mathieu, Y.; Beccia, M.R.; Bennati-Granier, C.; Biaso, F.; Fanuel, M.; Ropartz, D.; Guigliarelli, B.; Record, E.; Rogniaux, H. Single-domain flavoenzymes trigger lytic polysaccharide monooxygenases for oxidative degradation of cellulose. Sci. Rep. 2016, 6, 28276. [CrossRef]

37. Macheleidt, J.; Mattern, D.J.; Fischer, J.; Netzker, T.; Weber, J.; Schroeckh, V.; Valiante, V.; Brakhage, A.A. Regulation and role of fungal secondary metabolites. Annu. Rev. Genet. 2016, 50, 371-392. [CrossRef]

38. Yin, Z.Y.; Liu, H.Q.; Li, Z.P.; Ke, X.W.; Dou, D.L.; Gao, X.N.; Song, N.; Dai, Q.Q.; Wu, Y.X.; Xu, J.R.; et al. Genome sequence of Valsa canker pathogens uncovers a potential adaptation of colonization of woody bark. New Phytol. 2015, 208, 1202-1216. [CrossRef]

39. Shen, Q.; Liu, Y.Y.; Naqvi, N.I. Fungal effectors at the crossroads of phytohormone signaling. Curr. Opin. Microbiol. 2018, 46, 1-6. [CrossRef]

40. Irieda, H.; Inoue, Y.; Mori, M.; Yamada, K.; Oshikawa, Y.; Saitoh, H.; Uemura, A.; Terauchi, R.; Kitakura, S.; Kosaka, A.; et al. Conserved fungal effector suppresses PAMP-triggered immunity by targeting plant immune kinases. Proc. Natl. Acad. Sci. USA 2019, 116, 496-505. [CrossRef]

41. Baumler, A.; Fang, F.C. Host specificity of bacterial pathogens. CSH Perspect. Med. 2013, 3, a010041. [CrossRef]

42. Ray, S.; Singh, P.K.; Gupta, D.K.; Mahato, A.K.; Sarkar, C.; Rathour, R.; Singh, N.K.; Sharma, T.R. Analysis of Magnaporthe oryzae genome reveals a fungal effector, which is able to induce resistance response in transgenic rice line containing resistance gene, Pi54. Front. Plant Sci. 2016, 7, 1140. [CrossRef] [PubMed]

43. Kubicek, C.P.; Herrera-Estrella, A.; Seidl-Seiboth, V.; Martinez, D.A.; Druzhinina, I.S.; Thon, M.; Zeilinger, S.; Casas-Flores, S.; Horwitz, B.A.; Mukherjee, P.K.; et al. Comparative genome sequence analysis underscores mycoparasitism as the ancestral life style of Trichoderma. Genome Biol. 2011, 12, R40. [CrossRef] [PubMed]

44. Baroncelli, R.; Piaggeschi, G.; Fiorini, L.; Bertolini, E.; Zapparata, A.; Pè, M.E.; Sarrocco, S.; Vannacci, G. Draft Whole-genome sequence of the biocontrol agent Trichoderma harzianum T6776. Genome Announc. 2015, 3, e00647-15. [CrossRef]

45. Gioti, A.; Stajich, J.E.; Johannesson, H. Neurospora and the dead-end hypothesis: Genomic consequences of selfing in the model genus. Evolution 2013, 67, 3600-3616. [CrossRef] [PubMed]

46. Ellison, C.E.; Stajich, J.E.; Jacobson, D.J.; Natvig, D.O.; Lapidus, A.; Foster, B.; Aerts, A.; Riley, R.; Lindquist, E.A.; Grigoriev, I.V. Massive changes in genome architecture accompany the transition to self-fertility in the filamentous fungus Neurospora tetrasperma. Genetics 2011, 189, 55-69. [CrossRef] [PubMed]

47. Galagan, J.E.; Calvo, S.E.; Borkovich, K.A.; Selker, E.U.; Read, N.D.; Jaffe, D.; FitzHugh, W.; Ma, L.J.; Smirnov, S.; Purcell, S.; et al. The genome sequence of the filamentous fungus Neurospora crassa. Nature 2003, 422, 859-868. [CrossRef]

48. Zheng, P.; Xia, Y.; Xiao, G.; Xiong, C.; Hu, X.; Zhang, S.; Zheng, H.; Huang, Y.; Zhou, Y.; Wang, S.; et al. Genome sequence of the insect pathogenic fungus Cordyceps militaris, a valued traditional Chinese medicine. Genome Biol. 2011, 12, R116. [CrossRef]

49. Lu, Y.Z.; Luo, F.F.; Cen, K.; Xiao, G.H.; Yin, Y.; Li, C.R.; Li, Z.Z.; Zhan, S.; Zhang, H.Z.; Wang, C.S. Omics data reveal the unusual asexual-fruiting nature and secondary metabolic potentials of the medicinal fungus Cordyceps cicadae. BMC Genom. 2017, 18, 668. [CrossRef] 
50. Asai, S.; Ayukawa, Y.; Gan, P.; Masuda, S.; Komatsu, K.; Shirasu, K.; Arie, T. High-quality draft genome sequence of Fusarium oxysporum f. sp. cubense strain 160527, a causal agent of panama disease. Microbiol. Resour. Announc. 2019, 8, e00654-19. [CrossRef]

51. Walkowiak, S.; Rowland, O.; Rodrigue, N.; Subramaniam, R. Whole genome sequencing and comparative genomics of closely related Fusarium head blight fungi: Fusarium graminearum, F. meridionale and F. asiaticum. BMC Genom. 2016, 17, 1014. [CrossRef]

52. Varela, J.A.; Puricelli, M.; Montini, N.; Morrissey, J.P. Expansion and diversification of MFS transporters in Kluyveromyces marxianus. Front. Microbiol. 2019, 9, 3330. [CrossRef] [PubMed]

53. Koonin, E.V.; Aravind, L. The NACHT family-a new group of predicted NTPases implicated in apoptosis and MHC transcription activation. Trends Biochem. Sci. 2000, 25, 223-224. [CrossRef]

54. Daskalov, A.; Paoletti, M.; Ness, F.; Saupe, S.J. Genomic clustering and homology between HET-S and the NWD2 STAND protein in various fungal genomes. PLoS ONE 2012, 7, e34854. [CrossRef] [PubMed]

55. Aragona, M.; Minio, A.; Ferrarini, A.; Valente, M.T.; Bagnaresi, P.; Orrù, L.; Tononi, P.; Zamperin, G.; Infantino, A.; Valè, G.; et al. De novo genome assembly of the soil-borne fungus and tomato pathogen Pyrenochaeta lycopersici. BMC Genom. 2014, 15, 313. [CrossRef]

56. Karlsson, M.; Atanasova, L.; Jensen, D.F.; Zeilinger, S. Necrotrophic mycoparasites and their genomes. Microbiol. Spectr. 2017, 5, FUNK-0016-2016. [CrossRef]

57. Wang, X.X.; Peng, J.Y.; Sun, L.; Bonito, G.; Wang, J.; Cui, W.J.; Fu, Y.P.; Li, Y. Genome sequencing illustrates the genetic basis of the pharmacological properties of Gloeostereum incarnatum. Genes 2019, 10, 188. [CrossRef]

58. Simão, F.A.; Waterhouse, R.M.; Ioannidis, P.; Kriventseva, E.V.; Zdobnov, E.M. BUSCO: Assessing genome assembly and annotation completeness with single-copy orthologs. Bioinformatics 2015, 31, 3210-3212. [CrossRef]

59. Stanke, M.; Keller, O.; Gunduz, I.; Hayes, A.; Waack, S.; Morgenstern, B. AUGUSTUS: Ab initio prediction of alternative transcripts. Nucleic Acids Res. 2006, 34, W435-W439. [CrossRef]

60. Allen, J.E.; Majoros, W.H.; Pertea, M.; Salzberg, S.L. JIGSAW, GeneZilla, and GlimmerHMM: Puzzling out the features of human genes in the ENCODE regions. Genome Biol. 2006, 7 (Suppl. 1), S9. [CrossRef]

61. Holt, C.; Yandell, M. MAKER2: An annotation pipeline and genome-database management tool for second-generation genome projects. BMC Bioinform. 2011, 12, 491. [CrossRef]

62. Tatusov, R.L.; Galperin, M.Y.; Natale, D.A.; Koonin, E.V. The COG database: A tool for genome-scale analysis of protein functions and evolution. Nucleic Acids Res. 2000, 28, 33-36. [CrossRef] [PubMed]

63. Bairoch, A.; Apweiler, R. The SWISS-PROT protein sequence data bank and its new supplement TREMBL. Nucleic Acids Res. 1996, 24, 21-25. [CrossRef] [PubMed]

64. Ashburner, M.; Ball, C.A.; Blake, J.A.; Botstein, D.; Butler, H.; Cherry, J.M.; Davis, A.P.; Dolinski, K.; Dwight, S.S.; Eppig, J.T.; et al. Gene Ontology: Tool for the unification of biology. Nat. Genet. 2000, 25, 25-29. [CrossRef]

65. Kanehisa, M.; Furumichi, M.; Tanabe, M.; Sato, Y.; Morishima, K. KEGG: New perspectives on genomes, pathways, diseases and drugs. Nucleic Acids Res. 2016, 45, 353-361. [CrossRef] [PubMed]

66. Finn, R.D.; Mistry, J.; Schuster-Bockler, B.; Griffiths-Jones, S.; Hollich, V.; Lassmann, T.; Moxon, S.; Marshall, M.; Khanna, A.; Durbin, R.; et al. Pfam: Clans, web tools and services. Nucleic Acids Res. 2006, 34, D247-D251. [CrossRef] [PubMed]

67. Liu, W.; Xie, Y.; Ma, J.; Luo, X.; Nie, P.; Zuo, Z.; Lahrmann, U.; Zhao, Q.; Zheng, Y.; Zhao, Y.; et al. IBS: An illustrator for the presentation and visualization of biological sequences. Bioinformatics 2015, 31, 3359-3361. [CrossRef] [PubMed]

68. Cortázar, A.R.; Aransay, A.M.; Alfaro, M.; Oguiza, J.A.; Lavín, J.L. Secretool: Integrated secretome analysis tool for fungi. Amino Acids 2013, 46, 471-473. [CrossRef] [PubMed]

69. Rawlings, N.D.; Barrett, A.J.; Thomas, P.D.; Huang, X.; Bateman, A.; Finn, R.D. The MEROPS database of proteolytic enzymes, their substrates and inhibitors in 2017 and a comparison with peptidases in the PANTHER database. Nucleic Acids Res. 2018, 46, D624-D632. [CrossRef]

70. Urban, M.; Cuzick, A.; Rutherford, K.; Irvine, A.; Pedro, H.; Pant, R.; Sadanadan, V.; Khamari, L.; Billal, S.; Mohanty, S.; et al. PHI-base: A new interface and further additions for the multi-species pathogen-host interactions database. Nucleic Acids Res. 2017, 45, D604-D610. [CrossRef]

71. Lu, T.; Yao, B.; Zhang, C. DFVF: Database of fungal virulence factors. Database 2012, 2012, bas032. [CrossRef] 
72. Li, L.; Stoeckert, C.J.; Roos, D.S. OrthoMCL: Identification of ortholog groups for eukaryotic genomes. Genome Res. 2003, 13, 2178-2189. [CrossRef] [PubMed]

73. Sievers, F.; Higgins, D.G. Clustal omega for making accurate alignments of many protein sequences. Protein Sci. 2017, 27, 135-145. [CrossRef] [PubMed]

74. Stamatakis, A. RAxML version 8: A tool for phylogenetic analysis and post-analysis of large phylogenies. Bioinformatics 2014, 30, 1312-1313. [CrossRef] [PubMed]

75. De Bie, T.; Cristianini, N.; Demuth, J.P.; Hahn, M.W. CAFE: A computational tool for the study of gene family evolution. Bioinformatics 2006, 22, 1269-1271. [CrossRef] [PubMed]

76. Gao, F.L.; Chen, C.J.; Arab, D.A.; Du, Z.G.; He, Y.H.; Ho, S.Y.W. Easycodeml: A visual tool for analysis of selection using codeml. Ecol. Evol. 2019, 9, 3891-3898. [CrossRef]

(C) 2020 by the authors. Licensee MDPI, Basel, Switzerland. This article is an open access article distributed under the terms and conditions of the Creative Commons Attribution (CC BY) license (http://creativecommons.org/licenses/by/4.0/). 